Evaluating hedge fund performance: a stochastic dominance approach

By

Sheng Li

Oliver Linton

DISCUSSION PAPER NO 591

DISCUSSION PAPER SERIES

July 2007

Sheng Li obtained a BSc in Economics at Peking University and an MSc in Finance and Economics at LSE. He began a PhD in Finance at LSE in October 2002. His research interests include: asset pricing and risk management, market microstructure, risk and return in hedge funds. Oliver Linton is Professor of Econometrics in the Department of Economics, London School of Economics. He is Co-editor of Econometric Theory and Associate Editor of: Econometrica, The Journal of Econometrics and of The Journal of the American Statistical Association. Any opinions expressed here are those of the authors and not necessarily those of the FMG. The research findings reported in this paper are the result of the independent research of the authors and do not necessarily reflect the views of the LSE. 


\title{
Evaluating hedge fund performance: a stochastic dominance approach
}

\author{
Sheng $\mathrm{Li}^{*}$ \\ Oliver Linton ${ }^{\dagger}$ \\ London School of Economics \\ London School of Economics
}

July 24, 2007

\begin{abstract}
We introduce a general and flexible framework for hedge fund performance evaluation and asset allocation: stochastic dominance (SD) theory. Our approach utilizes statistical tests for stochastic dominance to compare the returns of hedge funds. We form hedge fund portfolios by using SD criteria and examine the out-of-sample performance of these hedge fund portfolios. Compared to performance of portfolios of randomly selected hedge funds and mean-variance efficient hedge funds, our results show that fund selection method based on SD criteria greatly improves the performance of hedge fund portfolio.
\end{abstract}

Keywords: Alpha; Mean Variance analysis; Portfolio; Risk Return

\section{Introduction}

Over the last decade, the number of hedge funds has risen by about 20 percent per year to reach around 8,500 in 2006. The amount of assets under management of the hedge fund industry has increased from around $\$ 40$ billion in 1990 to an estimated $\$ 1,130$ billion in 2006 . Since hedge funds typically use leverage, the positions that they take in the financial markets are large enough to move markets around the world. The rapid growth in hedge funds reflects the increasing importance of this alternative investment category for institutional investors and wealthy individual investors.

*Department of Finance, London School of Economics, Houghton Street, London WC2A 2AE, United Kingdom. E-mail address: S.Li4@lse.ac.uk.

${ }^{\dagger}$ Department of Economics, London School of Economics, Houghton Street, London WC2A 2AE, United Kingdom. E-mail address: o.linton@lse.ac.uk. 
Correspondingly, identifying hedge fund managers with superior skills and refining the traditional portfolio management tools to optimize investments in a large universe of hedge funds have also become challenging tasks in portfolio management. If the top hedge fund performance can be explained by superior skills owned by managers not by luck, we would expect top performance of such managers persists. However, there is little consensus on hedge fund performance persistence in the empirical finance literature. A number of studies find that hedge fund performance only persist at short term (one to three months) which might be due to hedge funds' illiquid exposure and there is no evidence of performance persistence at annual horizons.(see Getmansky, Lo, and Makarov, 2004, Brown, Goetzmann and Ibbotson, 1999, Agarwal and Naik, 2000, Liang, 2000, Bares, Gibson and Gyger, 2003, Boyson and Cooper, 2004, Baquero, Ter Horst and Verbeek, 2005). On the contrary, more recent study by Kosowskia, Naik and Teo (2006) finds that sorting hedge funds on Bayesian alphas yields a 5.5 percent per year increase in the alpha of the spread between the top and bottom hedge fund deciles. Hedge fund performance persists at annual horizon. Using a novel GMM procedure to estimate alpha for hedge fund managers, Jagannathan, Malakhov and Novikov (2006) find evidence of hedge fund managers' performance persistence over three year horizons.

More practical issue facing hedge fund investors is how to construct an efficient hedge fund portfolio or add hedge funds to the existing portfolio. The standard mean-variance approach to portfolio allocation, which is founded on the assumption of normal distributions and an objective function of maximizing risk-adjusted return, is inadequate when dealing with portfolios of hedge funds. A number of studies (see Lo, 2001, Amin and Kat, 2003) have shown that risk characteristics of hedge funds are substantially different from those of traditional investment pools because hedge fund managers usually employ highly dynamic trading strategy and use short selling, leverage, concentrated investments, and derivatives. Specifically, hedge fund returns are not normally distributed and exhibit significant skewness and kurtosis. They also tend to display significant co-skewness with the returns on other hedge funds as well as equity. Mean-variance models ignore these higher moments of the return distribution, and thus fail to take into consideration the benefits of funds that occasionally surprise on the upside while they also underestimate the risk of funds that have asymmetric downside risk. Despite the weakness of mean-variance frame work, it still dominates in practical hedge fund portfolio management. The Sharpe ratio is commonly used to quantify the risk-return trade-off. Amenc, Giraud, Martellini and Vaissie (2004) report that only $2 \%$ of the European multi-managers pay attention to skewness and kurtosis; while $84 \%$ of multi-manager funds consider that volatility is of major concern to their clients and $82 \%$ consider Sharpe ratio as an important indicator. A number of studies also address the issue of including hedge funds in standard institutional portfolios in mean-variance portfolio optimization. (see, Amenc and Martellini, 2002, Brunel, 2004, Kat, 2005, Till, 2005). 
Another strand of literature develops different frameworks for hedge fund allocation, which incorporate a variety of investment objectives, particularly investor preferences for skewness and kurtosis of returns, into portfolio optimization models. Using a Polynomial Goal Programming (PGP) optimization model, Davies, Kat and Lu (2005) solve for multiple competing hedge fund allocation objectives within a mean-variance-skewness-kurtosis frame-work and analyze different impacts of various hedge fund strategies on the distribution of optimal portfolio. Morton, Popova and Popova (2006) study hedge fund allocation issue by assuming a family of utility functions which are a weighted sum of the probability of achieving a benchmark and expected regret relative to another benchmark. They then use a Monte Carlo method to obtain a solution to the related portfolio optimization model. Alexander and Dimitriu (2004) develop a portfolio construction model by selecting funds according to their ranking of alpha estimated with factor models. They then allocate selected funds using constrained minimum variance optimization.

In this paper, we introduce a more general and flexible framework for hedge fund asset allocation — stochastic dominance (SD) theory. Our approach utilizes statistical tests for stochastic dominance to compare the returns of hedge funds. The theory of stochastic dominance (see, Hadar and Russell, 1969, Hanoch and Levy, 1969, Rothschild and Stiglitz, 1970, and Whitmore, 1970) provides a systematic framework for analyzing economic behavior under uncertainty. We form hedge fund portfolios by using SD criteria. We then examine the out-of-sample performance of these hedge fund portfolios. Compared to both randomly selected hedge fund portfolio and mean-variance efficient hedge fund portfolio, our results show that fund selection method based on SD criteria greatly improves the performance of hedge fund portfolio.

Our framework relying on stochastic dominance has several advantages. First, we are able to use the information embedded in the entire empirical return distributions of hedge funds instead of a finite set of sample statistics. Second, while mean-variance analysis is consistent with the expected utility theory only under relatively restrictive assumptions about investor preferences or the statistical distribution of the investment returns, SD criteria do not require a full parametric specification of investor preferences, but rather rely on general preference assumptions which are intuitively close to the real objectives of investors, for example, non-satiation in the case of first order stochastic dominance (FSD) and risk aversion in the case of second order stochastic dominance (SSD). This is important because the view of investors towards various hedge funds depends crucially on their investment objectives and risk preferences.

The reminder of the paper is organized as follows. Section 2 introduces stochastic dominance framework. Section 3 describes the data and reports the results of empirical analysis and a comparison of performance of various hedge fund portfolios constructed by using different criteria. Section 4 concludes. 


\section{Stochastic Dominance}

\subsection{First and Second Order Dominance}

Stochastic dominance theory provides a possible comparison relationship between two stochastic distributions. Stochastic dominance relations offer a general decision rule for decision making when facing the choice between random payoffs, given that the utility functions share some common characteristics such as non-satiation or risk-aversion. In this paper, we test for the first and second orders of stochastic dominance.

Let $X_{1}$ and $X_{2}$ be two outcome variables. Let $\mathcal{U}_{1}$ denote the class of all von Neumann-Morgenstern type utility functions, $u$, such that $u^{\prime} \geq 0$, (increasing). Also, let $\mathcal{U}_{2}$ denote the class of all utility functions in $\mathcal{U}_{1}$ for which $u^{\prime \prime} \leq 0$ (strict concavity). Let $F_{1}(x)$ and $F_{2}(x)$ denote the cumulative distribution functions, respectively.

Definition $1 X_{1}$ First Order Stochastic Dominates $X_{2}$, denoted $X_{1} \succeq_{F S D} X_{2}$, if and only if:

(1) $E\left[u\left(X_{1}\right)\right] \geq E\left[u\left(X_{2}\right)\right] \quad$ for all $u \in \mathcal{U}_{1}$, with strict inequality for some $u$; Or

(2) $F_{1}(x) \leq F_{2}(x) \quad$ for all $x$ with strict inequality for some $x$.

Definition $2 X_{1}$ Second Order Stochastic Dominates $X_{2}$, denoted $X_{1} \succeq_{S S D} X_{2}$, if and only if either: (1) $E\left[u\left(X_{1}\right)\right] \geq E\left[u\left(X_{2}\right)\right] \quad$ for all $u \in \mathcal{U}_{2}$, with strict inequality for some $u$; Or:

(2) $\int_{-\infty}^{x} F_{1}(t) d t \leq \int_{-\infty}^{x} F_{2}(t) d t$ for all $x$ with strict inequality for some $x$.

For any two outcomes $i, j$ define

$$
\delta_{i j}=\sup _{x \in \mathcal{X}} F_{i}(x)-F_{j}(x),
$$

where $\mathcal{X}$ is contained in the supports of $X_{i}, X_{j}$. Fund $i$ dominates fund $j$ if $\delta_{i j} \leq 0$. If a fund $X_{1}$ second order dominates fund $X_{2}$ then no risk averse individual would prefer $X_{2}$ to $X_{1}$. First order dominance of one outcome by another is even stronger: If a fund $X_{1}$ first order dominates fund $X_{2}$ then no individual who prefers more wealth to less would prefer $X_{2}$ to $X_{1}$. First order dominance implies second order dominance. Note that these concepts do not require the existence of moments of the underlying outcomes unlike mean variance analysis. Furthermore, both relations are transitive, i.e., if $X_{1}$ dominates $X_{2}$ and $X_{2}$ dominates $X_{3}$ then $X_{1}$ dominates $X_{3}$. However, neither relation denotes a full ordering, only a partial ordering. That is, we may not be able to rank two outcomes at all according to either relation. In such cases, one can either say one is indifferent between the two investments or one can impose more preference structure to discriminate between them. One possibility is to increase the dominance order to third order or fourth order etc., which reduces the set of noncomparability. Alternatively one can then supplement the partition induced by the dominance 
relation by some additional criterion like Sharpe ratio. In practice, although FSD implies strong relationship between two outcomes, it is not very discerning because the cumulative distributions of net returns of the two investment alternatives often intersect, in which case FSD cannot discriminate between the alternatives. For decision making under risk more important is SSD. If investors are risk averse and prefer more to less, SSD could be used to choose between two outcomes.

In empirical analysis, stochastic dominance analysis requires the comparison of the probability distributions of two outcomes which are unknown and must be estimated from available data. Various statistical tests for the existence of SD orders have been developed. Several tests proposed earlier (for example Anderson, 1996 and Davidson and Duclos, 2000) compare the distribution functions only at a fixed number of arbitrarily chosen points. In general, comparisons using only a small number of arbitrarily chosen points will have low power if there is a violation of the inequality in the null hypothesis on some subinterval lying between the evaluation points used in the test. More recent tests proposed by Barrett and Donald (2003) and Linton, Maasoumi and Whang (2003) compare the two distributions at all points in the sample.

\section{Empirical Results}

\subsection{Description of the data}

In this section, we provide an empirical analysis of hedge fund database under Stochastic Dominance framework. The database used in this paper covers the period January 1994 to August 2004 and was provided by the Center for International Securities and Derivatives Markets (CISDM). It has two parts: a total of 1,269 live hedge funds and 1,760 dead hedge funds. To reduce survivorship bias, we include both live and dead funds in our analysis. Each set consists of a performance file, containing monthly net-of-fee returns, total net assets, and net asset values, and a fund information file, containing fund name, strategy type, management fees, and other supplementary details. We select only those funds with at least 2 years of monthly observations. CISDM classifies funds according to 10 different sub types. Funds are further separated by different investment strategies. We analyze 5 fund strategies, namely Merger Arbitrage, Distressed Securities, Equity Hedge, Market Neutral, Convertible Arbitrage. Table 1 lists summary statistics of the hedge funds from CISDM database during the January 1994 to August 2004 period. For each strategy, the table lists the number of funds and means and standard deviations of basic summary statistics. 


\subsection{Stochastic Dominance}

To compare hedge fund returns using stochastic dominance concepts, our procedure includes two steps. First, we take into account the systematic risk exposure of hedge funds and obtain the riskadjusted returns of hedge funds. Then we test for FSD and SSD relations among risk-adjusted hedge fund returns relying on Linton, Maasoumi and Whang (2003) statistical test.

Risk adjustments for hedge fund returns are difficult due to their use of derivatives and dynamic trading strategies. Commonly used methods include using hedge fund indices and factor models. More recently, a number of studies (see Kat and Palaro (2005)) argue that sophisticated dynamic trading strategies involving liquid futures contracts can replicate many of the statistical properties of hedge-fund returns. Hasanhodzic and Lo (2006) estimate linear factor models for individual hedge funds using six common factors, and find that for certain hedge-fund style categories, a significant fraction of funds' expected return can be captured by common factors.

Here we use as performance benchmarks the seven-factor model developed by Fung and Hsieh (2004). The Fung and Hsieh (2004) factors are S\&P 500 return minus risk free rate (SNPMRF), Wilshire small cap minus large cap return (SCMLC), change in the constant maturity yield of the 10-year Treasury (BD10RET), change in the spread of Moody's Baa minus the 10-year Treasury (BAAMTSY), bond PTFS (PTFSBD), currency PTFS (PTFSFX), and commodities PTFS (PTFSCOM), where PTFS denotes primitive trend following strategy. Fung and Hsieh (2004) show that their factor model strongly explains variation in individual hedge fund returns.

In order to obtain risk-adjusted performance of hedge funds, we regress the net-of-fee monthly excess return (in excess of the risk free rate) of a hedge fund on the seven-factor model.

$$
R_{i, t}=\alpha_{i}+\beta_{i}^{\top} Z_{t}+\epsilon_{i, t}
$$

where $\beta_{i}$ represents the risk exposure of fund $\mathrm{i}$ at month $\mathrm{t}$ to the various factors, and $Z_{t}$ is the monthly value of different factors. The risk-adjusted return of fund $i$ at month $t$ is calculated as:

$$
\hat{\alpha}_{i, t}=R_{i, t}-\hat{\beta}_{i}^{\top} Z_{t}
$$

where $R_{i, t}$ is the raw return of fund i in month $\mathrm{t}, \hat{\beta}_{i}$ is the estimated risk exposure for fund i, and $Z_{t}$ is the value of the various factors at month $t$. We obtain the risk-adjusted returns as the intercept term of regressions. We plot the distribution of $\alpha$ in Figure 1.

We next conduct an analysis of the distributions of risk-adjusted returns of the funds, with a view to establishing stochastic dominance orderings. For each fund $i$ we compute the empirical c.d.f. 
and integrated c.d.f. [denoted s.d.f.] as follows

$$
\begin{aligned}
& \widehat{F}_{i}(x)=\frac{1}{T_{i}} \sum_{t=1}^{T_{i}} 1\left(X_{i t} \leq x\right) \\
& \widehat{S}_{i}(x)=\int_{-\infty}^{x} \widehat{F}_{i}\left(x^{\prime}\right) d x^{\prime}=\frac{1}{T_{i}} \sum_{t=1}^{T_{i}}\left(x-X_{i t}\right) 1\left(X_{i t} \leq x\right),
\end{aligned}
$$

where $X_{i t}=\hat{\alpha}_{i, t}$ is risk-adjusted return. We say that a fund $i$ is first order dominated if for some fund $j$

$$
\max _{1 \leq \ell \leq L} \widehat{F}_{j}\left(x_{\ell}\right)-\widehat{F}_{i}\left(x_{\ell}\right)<0
$$

where $x_{1}, \ldots, x_{L}$ is a grid of points contained in the union of the supports of the distributions. Likewise, for second order dominance.

Let $\mathcal{F}_{D}=\{i: i$ is first order dominated $\}$ and let $\mathcal{F}_{U}$ be the complement of this set in the full set of funds, likewise define $\mathcal{S}_{D}$ and $\mathcal{S}_{U}$. Clearly, $\mathcal{F}_{D} \subseteq \mathcal{S}_{D}$ and so $\mathcal{S}_{U} \subseteq \mathcal{F}_{U}$.

We compute the set of all funds that are undominated across all pairwise comparisons. We then construct a portfolio of all undominated funds. To examine the out-of-sample performance of undominated funds, we construct portfolios of funds $\mathcal{S}_{U}$ on January 1 each year (from 1999 to 2004), based on stochastic dominance orders of risk-adjusted hedge fund returns estimated over the prior five years. The portfolios are equally weighted monthly, so the weights are readjusted whenever a fund disappears. We also construct the portfolio of first-order dominated funds for comparison purpose. Given the economic intuition of stochastic dominance that any risk averse individual should choose funds in $\mathcal{S}_{U}$ and any investor who prefer more to less should not choose funds in $\mathcal{F}_{D}$, we expect portfolio of funds in $\mathcal{S}_{U}$ exhibit much better performance than portfolio of funds in $\mathcal{F}_{D}$.

To compare stochastic dominance tests with mean variance tests, we also construct portfolios of mean-variance efficient funds on January 1 each year (from 1999 to 2004), based on means and variances of funds estimated over the prior five years. A fund is defined as a mean-variance efficient fund if no other funds have both higher means and lower variances than this fund. Hence, funds are selected by comparing two summary statistics: the mean and the variance, which represents the distribution of hedge fund returns.

A number of studies find that hedge fund portfolio return properties vary substantially with the number of hedge funds included in the portfolio. See, Amin and Kat (2002), Davies, Kat and Lu (2003), Alexander and Dimitriu (2004). A hedge fund portfolio including only ten funds will typically have significantly higher variance than a similar hedge fund portfolio containing 100 funds. Therefore, to assess the robustness of SD analysis, we also construct representative portfolios containing the same number of funds as in $\mathcal{S}_{U}$ for each year (from 1999 to 2004). The funds in portfolios are randomly selected. 
Table 2 reports the number of hedge funds held by portfolios for each year and Table 3 reports summary statistics and alphas of portfolios constructed using different criteria. Alpha is estimated using the seven-factor model. As we can see in table 2, the number of funds in $\mathcal{S}_{U}$ is around 30 which is close to those of mean-variance efficient funds while the number of funds in $\mathcal{F}_{D}$ is substantially larger, ranging from 849 to 1225. French, Ko and Abuaf (2005) examine the current fund of hedge funds universe, and find that funds of hedge funds report holding between 1 and 200 underlying funds, and generally hold 10-30, with close to 20 on average. Hence, the number of holdings in $\mathcal{S}_{U}$ and mean-variance efficient sets is actually close to practitioner standards. Amin and Kat (2003) also find that the optimal size of well diversified hedge fund portfolios is in the range of 15 to 20.

According to Table 3, the mean return of portfolio of funds in $\mathcal{S}_{U}$ is 0.99 which is substantially larger than those of other portfolios. The first two moments of returns provide a great deal of the information about the investment outcome set of portfolios, but not everything. We find the skewness for portfolio of funds in $\mathcal{S}_{U}$ is 2.36 which is much larger than for other portfolios. Positive skewness means essentially that the big outcomes are on the upside so there is relatively little chance of large negatives. From a variety of points of view positive skewness is desirable.

Moreover, the portfolio of funds in $\mathcal{S}_{U}$ generates an alpha of 9.91 percent per year. As the tstatistics in column ten shows this alpha is statistically significant. The alphas of portfolios of funds in $\mathcal{F}_{D}$ and mean-variance efficient funds are also statistically significant but much lower than the alpha of portfolio of funds in $\mathcal{S}_{U}$. The alpha of the randomly picked funds portfolio is the lowest and statistically insignificant.

Figure 2,3,4 plot the time series of returns of these representative portfolios. We also plot the cumulative returns of representative portfolios in Figure 5. As we can see from the figure, the portfolio constructed by using SD criterion achieves a much higher cumulative return than those of other portfolios.

To further investigate the nature of the stochastic dominance approach, we establish stochastic orders within each investment category. We then repeat the above performance analysis. Table 4 reports the results for each category. We find that overall the portfolio of funds in $\mathcal{S}_{U}$ display superior performance in all categories. In particular, the portfolio of funds in $\mathcal{S}_{U}$ in the Merger arbitrage category achieve relative higher alpha than that of mean variance efficient funds. For equity neutral funds, the performance of stochastic dominance approach is not better than that of mean-variance approach.

It is also well documented that hedge fund returns exhibit substantial serial correlation, see Getmansky, Lo, and Makarov (2004) and Okunev and White (2003). They suggest that hedge funds' exposure to illiquid assets is the primary source of the strong observed serial correlation in hedge fund returns. To remove the effects of artificial serial correlation induced by illiquidity exposure, we 
adopt the methodology in Getmansky, Lo, and Makarov (2004) to unsmooth hedge fund returns and reduce serial correlation. Then, we re-do the above analysis on the unsmoothed sample of hedge fund returns. Overall, the performance of stochastic dominance approach still dominates other approaches.

\section{Conclusions}

In this paper, we introduce a general and flexible framework for hedge fund performance evaluation and asset allocation. Our approach utilizes recent advances in statistic tests for stochastic dominance. The approach is able to recognize and use the information embedded in the non-normal return distributions of hedge funds. To illustrate the method's ability to work with non-normal distributions, we form hedge fund portfolios by using SD criteria and examine the out-of-sample performance of these hedge fund portfolios. Compared to performance of portfolios of randomly selected hedge funds and mean-variance efficient hedge funds, our results show that fund selection method based on SD criteria greatly improves the performance of hedge fund portfolio.

There are a number of potential areas for improvement. First, the equal weighting of undominated funds can be replaced by more targeted weighting based on some univariate performance criterion like Sharpe ratio. Second, we could look at higher order dominance or asymmetric dominance notions like Prospect or Markowitz dominance. Third, we could take account of sampling variation in constructing the set of undominated funds by including those funds that are within some distance (controlled according to a statistical criterion like Type 1 error using the results of Linton, Maasoumi, and Whang (2003)) from being dominated. This would enlarge the set of undominated funds and it may not improve performance out of sample. Finally, although our SD test shows ability in distinguishing good funds from bad funds, it is restricted to pairwise comparison of a finite number of choice alternatives, and it has limitations with full diversification possibilities. The problem is that the ordering of the outcomes of a diversified portfolio of funds cannot be determined in a straightforward way from the orderings of the individual funds. Therefore, the ordering of each portfolio has to be determined individually. A number of recent studies recently developed Linear Programming (LP) tests for SD that do fully account for diversification. ${ }^{1}$ Post and Versijp (2006) develop tests for SSD and TSD efficiency that are embedded in the Generalized Method of Moments (GMM) framework. This test has superior statistical properties to the above LP tests and is a serious rival to the dominant mean-variance tests. We leave the application of these tests to hedge funds as future research.

\footnotetext{
${ }^{1}$ See Post (2003), Kuosmanen (2004), Post and Levy (2005) and Post and van Vliet (2006)
} 


\section{References}

[1] Agarwal, V., and N. Y. Naik, 2000, Multi-Period Performance Persistance Analysis of Hedge Funds, Journal of Financial and Quantitative Analysis, 35, 327-342.

[2] Alexander, C. and A. Dimitriu, 2004, The Art of Investing in Hedge Funds:. Fund Selection and Optimal Allocations, working paper, ISMA Centre, University of Reading.

[3] Amenc, N. and L. Martellini, 2002, Portfolio Optimization and Hedge Fund Style Allocation Decisions, The Journal of Alternative Investments, Vol. 5., No. 2, pp. 7-20.

[4] Amenc, N., J. Giraud, L. Martellini and M. Vaissie, 2004, Taking a close look at the European fund of Hedge Funds Industry: Comparing and Contrasting Industry Practices and Academic Recommendation, Journal of Alternative Investments, 59-69 .

[5] Amin, G.S., and H. Kat, 2003, Hedge Fund Performance 1990-2000: Do the Money Machines Really Add Value?, Journal of Financial and Quantitative Analysis, Vol. 38, No.2, pp. 251-274.

[6] Anderson, G.J., 1996, Nonparametric tests of stochastic dominance in income distributions, Econometrica 64, 1183-1193.

[7] Baquero, G., J. Ter Horst, and M. Verbeek, 2005, Survival, Look-Ahead Bias and the Persistence in Hedge Fund Performance, Journal of Financial and Quantitative Analysis, 40, 493-517.

[8] Bares, P.-A., R. Gibson, and S. Gyger, 2003, Performance in the Hedge Fund Industry: An Analysis of Short and Long-Term Persistence, Journal of Alternative Investments, 6, 25-41.

[9] Barrett, G. and S. Donald, 2003, Consistent Tests for Stochastic Dominance, unpublished manuscript, Dept. of Economics, Univ. of New South Wales.

[10] Boyson, N. M., and M. J. Cooper, 2004, Do Hedge Funds Exhibit Performance Persistence? A New Approach, Working Paper.

[11] Brown, S. J., W. N. Goetzmann, and R. G. Ibbotson, 1999, Offshore Hedge Funds: Survival and Performance 1989-1995, Journal of Business, 72, 91-118.

[12] Brunel, J., 2004, Revisiting the Role of Hedge Funds in Diversified Portfolios, The Journal of Wealth Management, 35-48

[13] Cremers, J., Kritzman M. and S. Page, 2005, Optimal Hedge Fund Allocation, Journal of Alternative Investments, 70-81. 
[14] Davidson, R. and J-Y. Duclos, 2000, Statistical inference for stochastic dominance and for the measurement of poverty and inequality, Econometrica 68, 1435-1464.

[15] Davies, R. J., H. M. Kat, and S. Lu, 2005, Fund of Hedge Funds Portfolio Selection: A MultipleObjective Approach, Cass Business School Research Paper

[16] French, C. W., D. B. Ko, and D. N.Abuaf, 2005, Diversification and Persistence in Hedge Funds.

[17] Fung, W. and D. Hsieh, 2004, Hedge Fund Benchmarks: A Risk-Based Approach, Financial Analysts Journal 60, 65-80.

[18] Getmansky, M., A. W. Lo, and I. Makarov, 2004, An Econometric Model of Serial Correlation and Illiquidity in Hedge Fund Returns, Journal of Financial Economics 74, 529 - 609.

[19] Hadar, J., and W.R. Russell ,1969, Rules for Ordering Uncertain Prospects, American Economic Review 59, 25-34.

[20] Hanoch, G., and H. Levy, 1969, The Efficiency Analysis of Choices Involving Risk, Review of Economic Studies 36, 335-346.

[21] Hasanhodzic, J. and A. W. Lo, 2006, Can Hedge-Fund Returns Be Replicated?: The Linear Case, working paper.

[22] Jagannathan, R., A. Malakhov and D. Novikov, 2006, Do Hot Hands Persist Among Hedge Fund Managers? An Empirical Evaluation, NBER Working Paper No. W12015.

[23] Kat, H., 2005, Integrating Hedge Funds into the Traditional Portfolio, The Journal of Wealth Management, 51-57.

[24] Kat, H. and H. Palaro, 2005, Who Needs Hedge Funds? A Copula-Based Approach to Hedge Fund Return Replication, Alternative Investment Research Centre Working paper No. 27, Cass Business School, City University, London.

[25] Kosowski, R., N.Y. Naik and M. Teo, 2006, Do Hedge Funds Deliver Alpha? A Bayesian and Bootstrap Analysis, Journal of Financial Economics

[26] Liang, B., 2000, Hedge Funds: The Living and the Dead, Journal of Financial and Quantitative Analysis, 35, 309-326.

[27] Linton, O., E. Maasoumi, and J. Whang ,2003, Consistent Testing for Stochastic Dominance under General Sampling Schemes, Review of Economic Studies 72, 735-765. 
[28] Lo, A.W., 2001, Risk Management for Hedge Funds: Introduction and Overview. Financial Analysts Journal, Vol. 57, No. 6, pp.16-33.

[29] Morton, D., E. Popova, and I. Popova, 2006, Efficient fund of hedge funds construction under downside risk measures, Journal of Banking and Finance 30:503-518.

[30] Okunev, J. and D. White, 2003, Hedge Fund Risk Factors and Value at Risk of Credit Trading Strategies, Working paper, Principal Global Investors and University of New South Wales.

[31] Popova, I., D.P. Morton, and E. Popova, 2003, Optimal hedge fund allocation with aysmmetric preferences and distributions, Technical Report, The University of Texas at Austin.

[32] Popova, I., D.P. Morton, and E. Popova, 2006, Efficient Fund of Hedge Fund Construction Under Downside Risk Measures, Journal of Banking and Finance, 30 503-518.

[33] Post, T., 2003, Stochastic Dominance in case of Portfolio Diversification: Linear Programming Tests, Journal of Finance 58:5.

[34] Post, T. and H. Levy, 2005, Does Risk Seeking Drive Stock Prices? A Stochastic Dominance Analysis of Aggregate Investor Preferences and Beliefs, Review of Financial Studies, 18, 925-953.

[35] Post, T. and P. van Vliet, 2006, Downside Risk and Asset Pricing, Journal of Banking and Finance.

[36] Post, T. and P. Versijp, 2006, Multivariate tests for stochastic dominance efficiency of a given portfolio, Journal of Financial and Quantitative Analysis.

[37] Rothschild, M., and J.E. Stiglitz, 1970, Increasing Risk I: A Definition, Journal of Economic Theory 2, 225-243.

[38] Till, H., 2005, On the Role of Hedge Funds in Institutional Portfolios, The Journal of Alternative Investments, 77-89.

[39] Whitmore, G.A., 1970, Third-Degree Stochastic Dominance, American Economic Review 60, 457-459. 


\section{Tables}

Table 1

\section{Summary Statistics of hedge fund returns}

This table presents means and standard deviations of basic summary statistics for funds in the CIDSM database over the sample period January 1994 to August 2004. SD denotes standard deviations. $\hat{\rho}_{1} \%$ and $\hat{\rho}_{2} \%$ denote first order and second order autocorrelation respectively. $\mathrm{N}$ is the number of funds.

\begin{tabular}{|c|c|c|c|c|c|c|c|c|c|c|c|c|}
\hline \multirow[t]{2}{*}{ Category } & \multicolumn{2}{|c|}{ Mean } & \multirow{2}{*}{\multicolumn{2}{|c|}{$\frac{\mathrm{SD}}{\text { Mean SD }}$}} & \multicolumn{2}{|c|}{ Skewness } & \multicolumn{2}{|c|}{ Kurtosis } & \multirow{2}{*}{$\begin{array}{l}\hat{\rho}_{1} \% \\
\text { Mean }\end{array}$} & \multicolumn{3}{|c|}{$\hat{\rho}_{2} \%$} \\
\hline & Mean & $\mathrm{SD}$ & & & Mean & $\mathrm{SD}$ & Mean & $\mathrm{SD}$ & & $\mathrm{SD}$ & Mean & $\mathrm{SD}$ \\
\hline Market neutral & 0.96 & 0.57 & 3.88 & 2.98 & 0.44 & 1.19 & 6.57 & 5.70 & 13.85 & 17.72 & 7.54 & 15.27 \\
\hline Equity hedge & 0.99 & 0.84 & 5.18 & 2.74 & 0.01 & 1.10 & 6.40 & 4.85 & 13.99 & 16.23 & 6.88 & 14.16 \\
\hline Distressed securities & 1.08 & 0.59 & 3.82 & 3.01 & -0.14 & 1.34 & 7.83 & 6.36 & 18.63 & 16.85 & 7.81 & 13.63 \\
\hline Merger arbitrage & 0.89 & 0.54 & 3.04 & 3.72 & -0.17 & 1.14 & 6.70 & 5.20 & 20.67 & 15.82 & 11.63 & 15.57 \\
\hline Convertible arbitrage & 1.02 & 0.51 & 2.11 & 1.71 & -0.14 & 1.38 & 7.18 & 5.33 & 30.93 & 17.31 & 12.81 & 16.87 \\
\hline
\end{tabular}




\section{Table 2}

This table reports the numbers of funds held in portfolios for each year (1999-2004). $\mathrm{N}$ is the number of funds.

\begin{tabular}{lcccc}
\hline Year & Total N of funds & $\mathrm{N}$ of funds in $F_{D}$ & $\mathrm{~N}$ of funds in $S_{U}$ & $\mathrm{~N}$ of MV efficient funds \\
\hline 1999 & 1054 & 849 & 13 & 29 \\
2000 & 1269 & 947 & 20 & 27 \\
2001 & 1405 & 1074 & 22 & 26 \\
2002 & 1532 & 1046 & 37 & 27 \\
2003 & 1582 & 1084 & 30 & 30 \\
2004 & 1639 & 1225 & 19 & 28 \\
\hline
\end{tabular}


Table 3

Statistical summary of returns for representative portfolios

This table reports summary statistics of returns for portfolios constructed using different criteria over the sample period: Janury 1999 to August 2004.

\begin{tabular}{lccccccccc}
\hline & Mean & Median & Max & Min & Std.Dev. & Skew & Kurtosis & $\begin{array}{c}\text { Alpha } \\
\text { (pct/year) }\end{array}$ & $\begin{array}{c}\text { t-stat } \\
\text { of alpha }\end{array}$ \\
\hline funds in $S_{U}$ & 0.99 & 0.83 & 13.09 & -3.25 & 2.42 & 2.36 & 11.98 & 9.91 & 3.25 \\
MV efficient funds & 0.66 & 0.65 & 6.71 & -2.56 & 1.49 & 1.30 & 7.61 & 6.95 & 3.93 \\
funds in $F_{D}$ & 0.48 & 0.50 & 6.07 & -3.98 & 2.04 & 0.04 & 2.91 & 4.42 & 3.66 \\
funds randomly picked & 0.32 & 0.01 & 8.08 & -4.96 & 2.30 & 0.55 & 4.13 & 2.19 & 1.12 \\
\hline
\end{tabular}


Table 4

Statistical summary of returns for representative portfolios within different styles

Mean Median Max Min Std.Dev. Skew Kurtosis Alpha t-stat

(pct/year) of alpha

\begin{tabular}{lccccccccc}
\hline Equity hedge & & & & & & & & & \\
funds in $S_{U}$ & 1.28 & 0.35 & 27.78 & -4.49 & 4.43 & 3.57 & 20.59 & 0.89 & 1.96 \\
MV efficient funds & 1.37 & 0.63 & 19.38 & -3.34 & 3.98 & 2.32 & 9.59 & 1.05 & 2.53 \\
funds randomly picked & 0.9 & 0.62 & 12.01 & -5.05 & 4.99 & 1.03 & 8.91 & 0.86 & 1.85 \\
\hline Equith neutral & & & & & & & & & \\
funds in $S_{U}$ & 0.94 & 0.75 & 11.91 & -2.49 & 1.84 & 3.11 & 19.81 & 0.81 & 4.36 \\
MV efficient funds & 0.94 & 0.84 & 9.87 & -2.69 & 1.65 & 2.22 & 14.04 & 0.86 & 5.03 \\
funds randomly picked & 0.71 & 0.49 & 5.54 & -3.58 & 1.75 & 0.19 & 3.62 & 0.64 & 3.82 \\
\hline Merger arbitrage & & & & & & & & & \\
funds in $S_{U}$ & 0.81 & 0.8 & 6.77 & -3.05 & 1.59 & 0.74 & 5.75 & 0.71 & 4.38 \\
MV efficient funds & 0.59 & 0.54 & 4.16 & -1.65 & 0.84 & 0.93 & 6.82 & 0.53 & 5.73 \\
funds randomly picked & 0.53 & 0.52 & 10.54 & -6.45 & 2.71 & 0.54 & 5.41 & 0.29 & 1.22 \\
\hline Distressed securities & & & & & & & & & \\
funds in $S_{U}$ & 1.05 & 0.96 & 4.05 & -2.68 & 1.39 & -0.15 & 3.37 & 1.02 & 6.78 \\
MV efficient funds & 1.05 & 1.04 & 5.08 & -3.38 & 1.53 & 0.01 & 3.41 & 1.02 & 6.59 \\
funds randomly picked & 0.92 & 0.65 & 4.97 & -2.82 & 2.13 & 1.48 & 8.51 & 0.82 & 4.29 \\
\hline Convertible arbitrage & & & & & & & & & 8.3 \\
funds in $S_{U}$ & 1.07 & 0.97 & 4.83 & -0.89 & 0.89 & 1.45 & 7.34 & 1.03 & 8.29 \\
MV efficient funds & 0.94 & 0.88 & 2.8 & -0.53 & 0.62 & 0.46 & 4.05 & 0.92 & 5.62 \\
funds randomly picked & 0.92 & 0.9 & 3.76 & -1.34 & 0.97 & 0.31 & 3.69 & 0.89 & \\
\hline
\end{tabular}




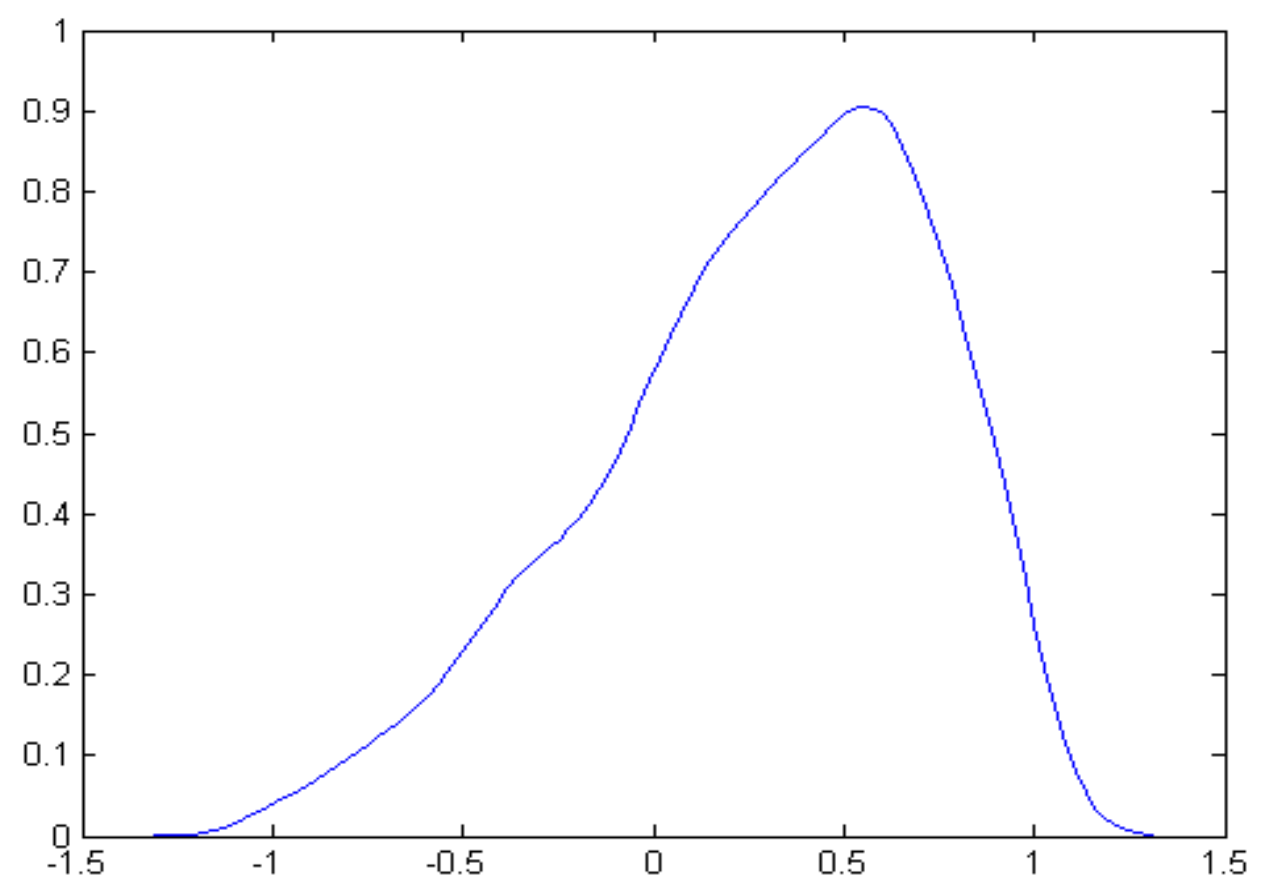

Figure1: Cross-section estimates of alpha

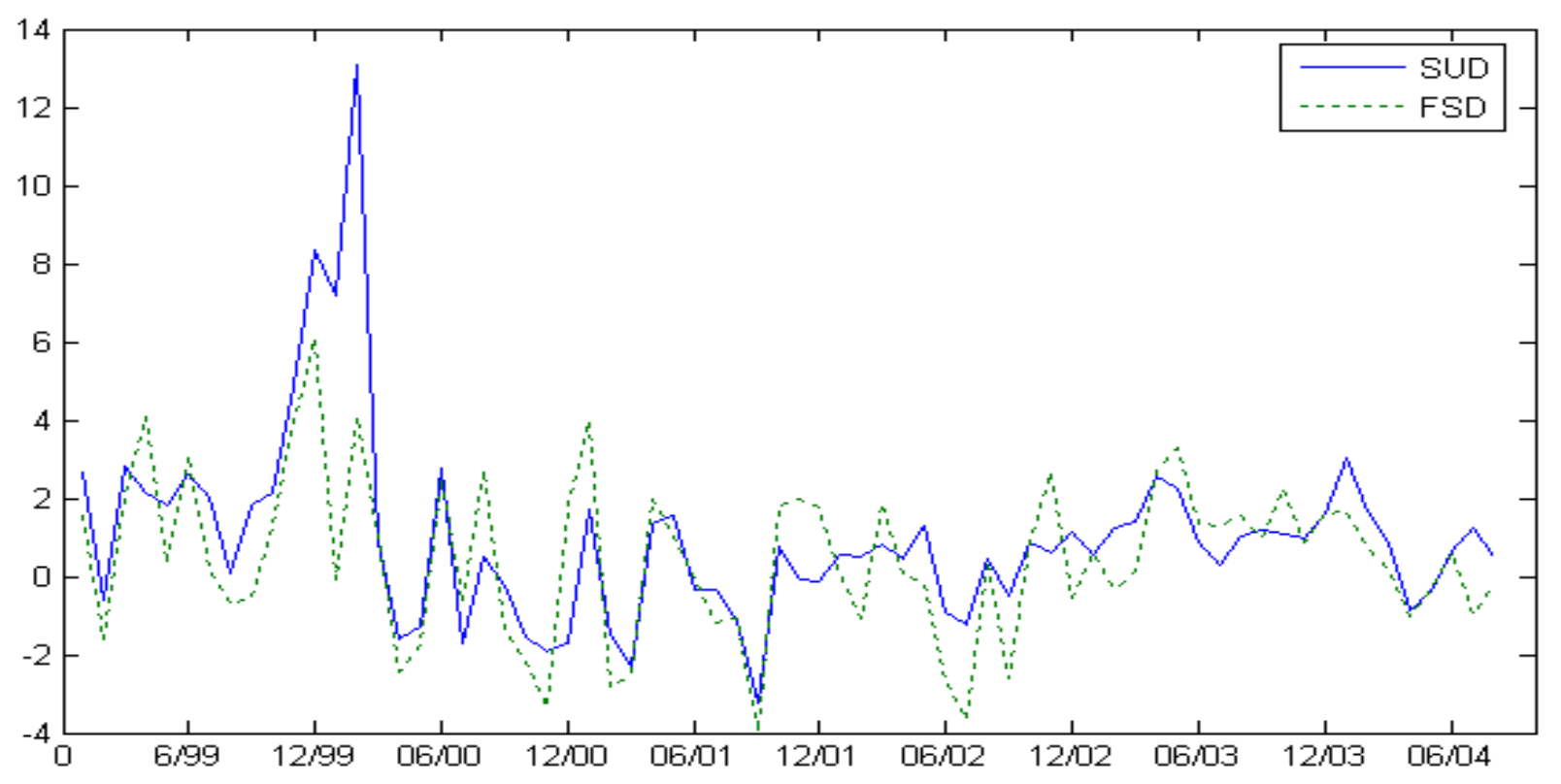

Figure 2: Plot of returns of portfolio of funds in SU and of funds in FD (01/1999 to 08/2004) 


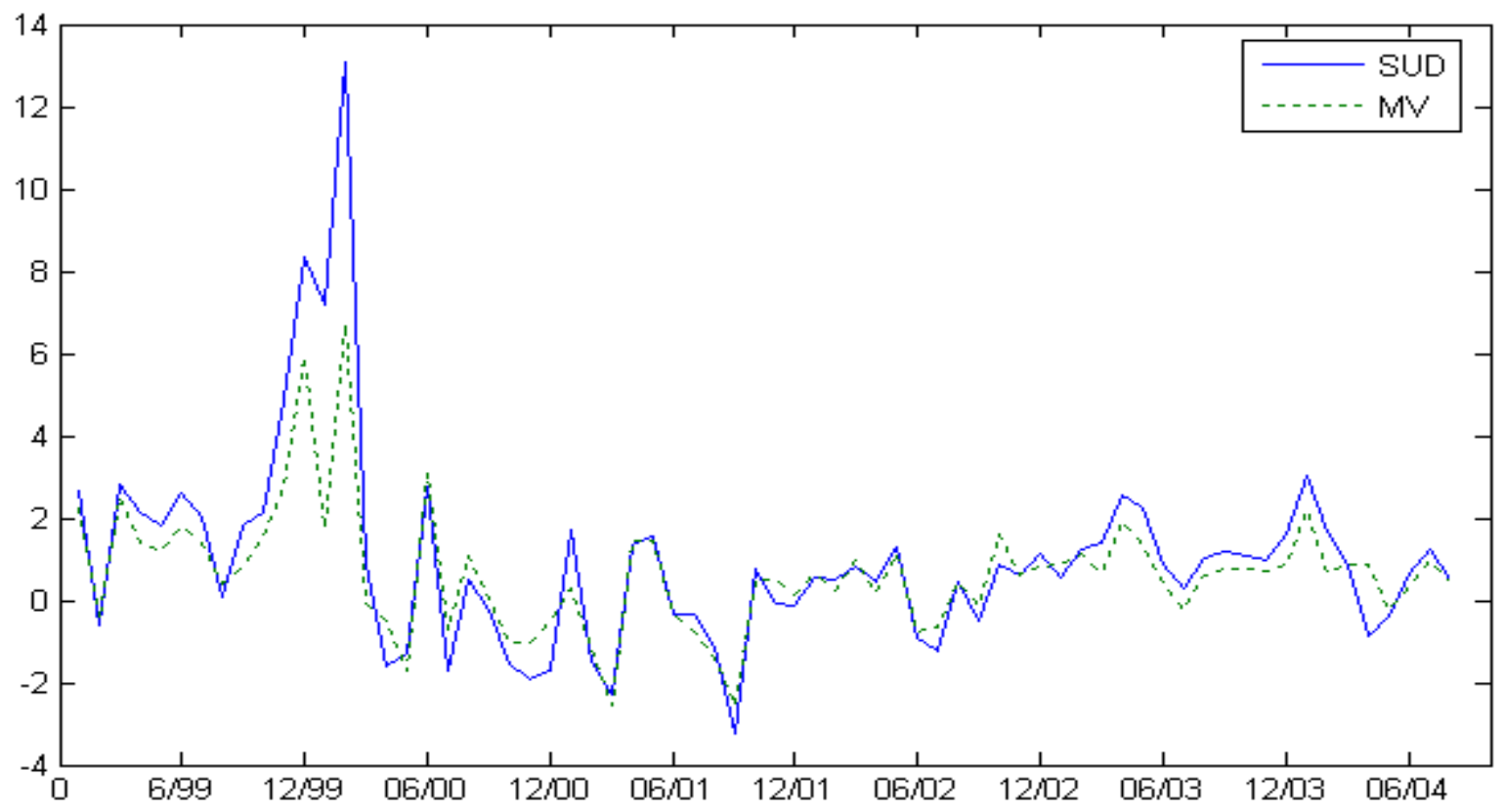

Figure 3: Plot of returns of portfolio of funds in SU and of MV efficient funds (01/1999 to 08/2004)

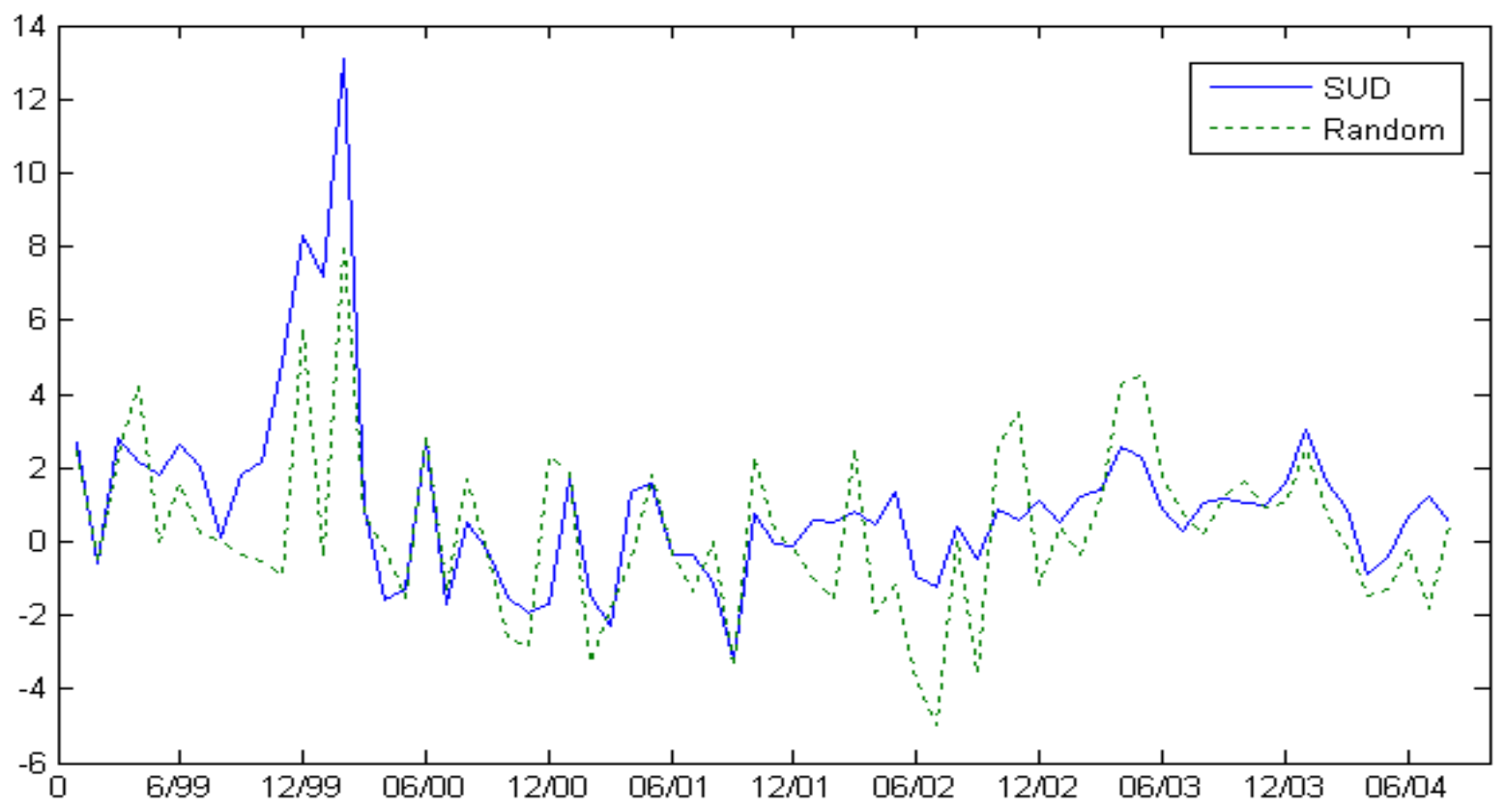

Figure 4: Plot of returns of portfolio of funds in SU and of randomly picked funds (01/1999 to 08/2004) 


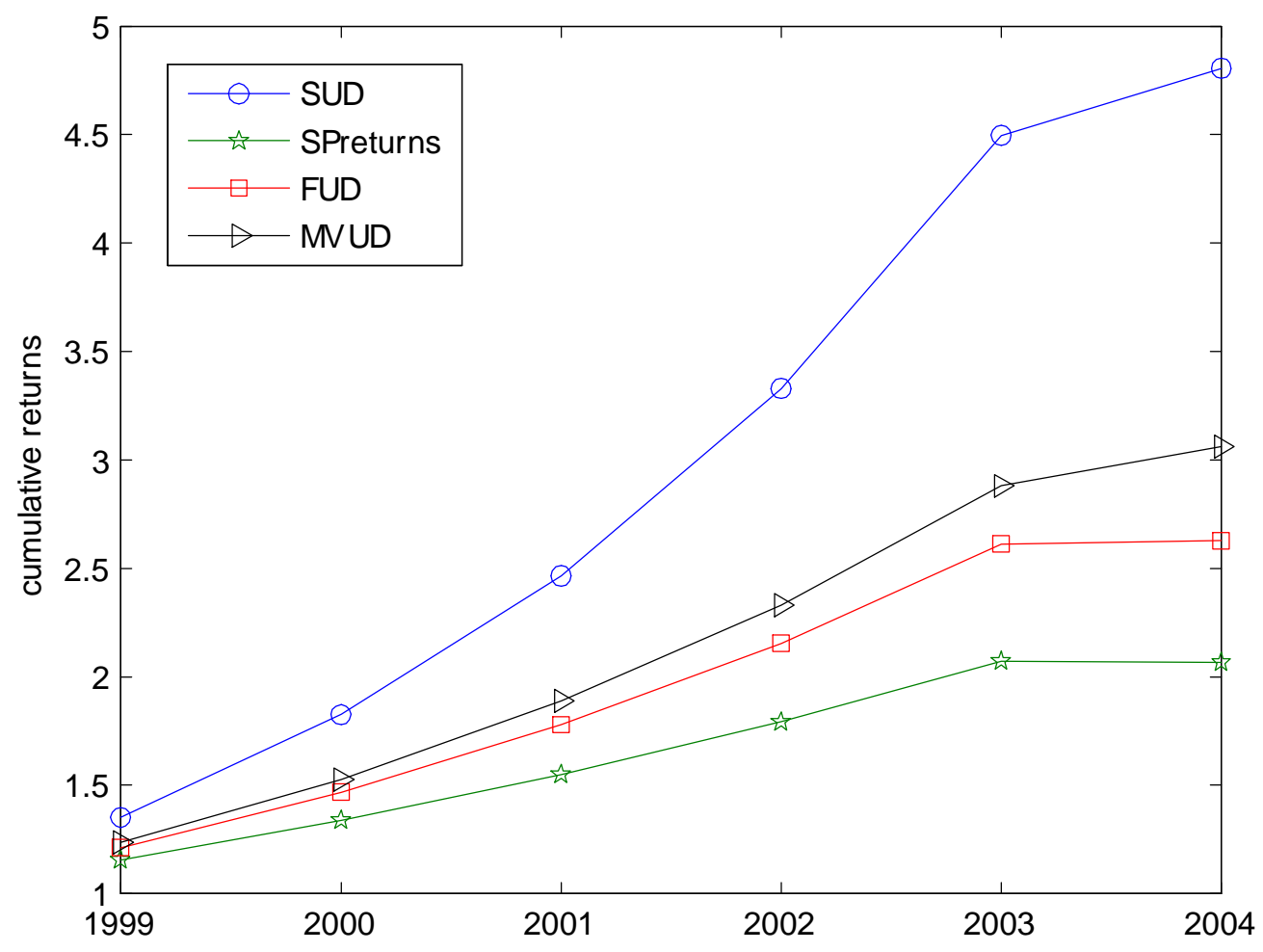

Figure 5. Plot of cumulative returns of representative portfolios 